\title{
A Multiplex qPCR Assay for Detection and Quantification of Plasmodiophora brassicae in Soil
}

\author{
Abhinandan Deora, Department of Plant Agriculture, University of Guelph, ON N1G 2W1, Canada; Bruce D. Gossen, Agriculture and Agri- \\ Food Canada, Saskatoon Research Centre, SK S7N 0X2, Canada; and Sasan Amirsadeghi and Mary Ruth McDonald, Department of Plant \\ Agriculture, University of Guelph, ON N1G 2W1, Canada
}

\begin{abstract}
Deora, A., Gossen, B. D., Amirsadeghi, S., and McDonald, M. R. 2015. A multiplex qPCR assay for detection and quantification of Plasmodiophora brassicae in soil. Plant Dis. 99:1002-1009.

Various physical and chemical factors in soil can inhibit the detection and quantification of soilborne plant pathogens using quantitative polymerase chain reaction (qPCR) assays. A multiplexed TaqMan qPCR assay, including a competitive internal positive control (CIPC), was developed to identify and (where necessary) compensate for inhibition in the quantification of resting spores of Plasmodiophora brassicae from soil. The CIPC amplicon was developed by modifying a sequence coding for green fluorescent protein so that it could be amplified with $P$. brassicaespecific primers. Addition of CIPC at $5 \mathrm{fg} / \mu \mathrm{l}$ to the singleplex qPCR assay designed to quantify $P$. brassicae genomic DNA did not reduce the sensitivity, specificity, or reproducibility of the assay. Each of the soil samples, either artificially inoculated or naturally infested with $P$. brassicae,

exhibited no amplification of the CIPC. When the samples were diluted and reassessed, the quantification cycle of the CIPC relative to the control (water only) was delayed in each sample. The magnitude of the delay was used to adjust the estimate of resting spore concentration. The corrected concentration estimates were significantly higher than the unadjusted estimate, which indicated the presence of DNA inhibitors in samples even after dilution. The only exception was a mineral soil sample inoculated with a low concentration $\left(10^{3}\right.$ spores $\left./ g\right)$ of resting spores. The assay was optimized for use on a range of soil types. A sample of $0.25 \mathrm{~g}$ for mineral soil and $0.10 \mathrm{~g}$ for high-organic-matter soil was optimum for recovery of DNA of $P$. brassicae. The assay represents an improvement over existing assays for estimating resting spore concentration in infested fields.
\end{abstract}

Clubroot, caused by Plasmodiophora brassicae (Woronin), is one of the most destructive diseases of cruciferous vegetable and oilseed crops worldwide (7), causing losses of up to $100 \%$ in severely infested fields (8). Soilborne resting spores of this obligate pathogen are the sole primary source of inoculum. They are easily disseminated (24) and can remain dormant in soil for many years (28). As a result, accurate assessment of resting spore populations in soil is important for limiting the spread of the pathogen.

In Canada, clubroot has historically been a disease of Brassica vegetables (16). However, since the first report of clubroot on canola (Brassica napus L.) on the Canadian prairies in 2003, the pathogen has been spreading rapidly (24). In the last decade, the disease has been confirmed in more than 1,400 canola fields and represents a substantial threat to the canola industry across the region (24). Resting spore populations in soil build up quickly on susceptible canola cultivars. These resting spores are introduced to noninfested fields primarily on vehicles and farm equipment but may occasionally be transported over long distances by wind and water erosion (11).

There are several methods for assessing resting spore populations in soil but each method has significant drawbacks. The resting spores of $P$. brassicae are small ( 3 to $5 \mu \mathrm{m}$ ) and lack characteristic ornamentation that aids in quick, accurate identification. As a result, extracting and quantifying resting spores by microscopy is time consuming (31) and the results can be highly variable. Detection of $P$. brassicae in plant tissues by polymerase chain reaction (PCR) or quantitative (q)PCR assays is a standard practice that has been extended to quantification of resting spores in soil $(10,21,28)$. However, several soil components such as clay particles, humic acids, pheonolic compounds, heavy metals, and assorted contaminants can inhibit PCR and reduce the reliability of quantification. Inhibitors are present at

Corresponding author: B. D. Gossen; E-mail: Bruce.Gossen@agr.gc.ca

Accepted for publication 28 January 2015.

http://dx.doi.org/10.1094/PDIS-06-14-0608-RE

(C) 2015 The American Phytopathological Society different levels in soils and are difficult to eliminate (2). Therefore, an internal control (IC) is generally included in PCR assays to quantify inhibition in each sample, in a parallel reaction or together with the target sample (multiplexed). Most of the qPCR assays for $P$. brassicae lack an IC $(4,9,17,21,29)$ or it is included in a parallel reaction (27). The advantage of multiplexing is that it saves time and resources. It also allows for reduced dilution of samples, which should increase the likelihood of detection of low-pathogen populations (3).

Multiplex TaqMan assays have been developed for quantification of various plant pathogens from seed, plants, and soil $(2,25,26)$. In the majority of these assays, two separate primer pairs were used for amplification of the IC and the target region. A major drawback of these assays is primer interference, which can reduce amplification efficiency. To eliminate primer interference, a competitive internal positive control (CIPC) approach has been used for detection and quantification of human pathogens from environmental sources $(12,13,19,23)$ and, recently, for quantification of Verticillium dahlaie (3). In this approach, the CIPC is a nontarget amplicon of exogenous DNA, with primer-binding regions identical to those of the target sequence, an internal sequence similar to the target sequence in length and base composition, and a unique region where the probe binds to the amplicon that differentiates the CIPC from the target locus $(15,22)$. These features ensure amplification of both the CIPC and the target locus with one primer pair only. Furthermore, a concentration of the CIPC is used such that it does not interfere with detection and quantification of target DNA.

The objective of our study was to develop a multiplex real-time qPCR assay for detection and accurate quantification of $P$. brassicae. It included development of a CIPC and validation of the method for use on field soils via assessment of soil samples inoculated with resting spores of $P$. brassicae.

\section{Materials and Methods}

Isolates of $\boldsymbol{P}$. brassicae. A resting spore suspension of $P$. brassicae pathotype 6 was prepared from clubbed roots of canola ('46A76'; Pioneer Hi-Bred, Ontario, Canada) collected from the Muck Crop Research Station of the University of Guelph in fall 2011 and stored at $-4^{\circ} \mathrm{C}$ until used. After grinding the roots using a commercial grinder, plant material was removed from the suspension by passage 
through 16 layers of cheesecloth and then a 40- $\mu \mathrm{m}$ sieve, which yielded a clean suspension of resting spores. The spore suspension was used to prepare a serial dilution and artificially inoculate soil samples in subsequent experiments. Pathotyping of all of the isolates used in the study were based on Williams' differential system (32).

Primer and probe specificity. The forward primer (DC1F) was reported previously in a SYBR Green assay for P. brassicae (4) and the reverse primer $(\mathrm{DC} 1 \mathrm{mR})$ was slightly modified (the last nucleotide on the $3^{\prime}$ end was deleted) (Table 1). DC1F and DC1mR amplified a 90-bp fragment of the internal transcribed spacer 1 region of $P$. brassicae. A probe (PB1; Table 1) with the $5^{\prime}$ end reporter dye of FAM and $3^{\prime}$ quencher of NFQ-MGB was used. PB1 was selected based on a preliminary assessment of three probes designed with different annealing temperatures, lengths, and GC contents. Its annealing temperature was approximately $10^{\circ} \mathrm{C}$ higher than the PCR primers.

To test the specificity of the primers and probes to $P$. brassicae, pathotypes $2,3,5,6$, and 8 were tested using qPCR. These isolates were originally obtained from clubroot-infested canola roots from sites across Canada (6). The inoculum for these pathotypes was prepared from clubbed roots of Shanghai pak choy (B. rapa subsp. chinensis 'Mei Qing Choi') grown under controlled conditions (photoperiod of 16 and $8 \mathrm{~h}$, day and night temperatures of 24 and $18^{\circ} \mathrm{C}$, respectively) and stored at $-4^{\circ} \mathrm{C}$. In addition, DNA from a number of fungal species was used to evaluate the specificity of the assay (Table 2). Each isolate was grown on commercial potato dextrose agar medium (SigmaAldrich, St. Louis). Genomic DNA (gDNA) was extracted from two replicates of each of the $P$. brassicae pathotypes $\left(10^{8}\right.$ resting spores) and from a mycelial mat ( 2 by $2 \mathrm{~cm}$ ) of each fungal species culture using a Power Soil DNA isolation kit according to the manufacturer's instructions (MO BIO Laboratories, Inc., Carlsbad, CA). Primer and probe specificity was further confirmed by conventional PCR analysis.

qPCR. The qPCR assays were conducted in a 48-well Step-One real-time PCR system (Applied Biosystems, CA) according to the manufacturer's instructions. Each $20-\mu l$ reaction mixture consisted of $10 \mu \mathrm{l}$ of $2 \times$ TaqMan Universal PCR Master Mix (P/N 4304437; Applied Biosystems), $0.8 \mu \mathrm{l}$ of $22.5 \mu \mathrm{M} P$. brassicae primer pairs, $0.8 \mu \mathrm{l}$ of $6.25 \mu \mathrm{M} P$. brassicae probe, and $2 \mu \mathrm{l}$ of target DNA. Two experimental replicates were used for each concentration of the standard series. There were two technical repetitions for each experimental replicate of each treatment in each assay, unless otherwise stated. A negative control sample (Hypure Molecular Biology Grade Water; Hyclone Laboratories Inc., Logan, UT) was also included in each assay. The thermal cycling conditions were $50^{\circ} \mathrm{C}$ for $2 \mathrm{~min}, 95^{\circ} \mathrm{C}$ for $10 \mathrm{~min}, 40$ cycles of $95^{\circ} \mathrm{C}$ for $15 \mathrm{~s}$, followed by $62^{\circ} \mathrm{C}$ for $1 \mathrm{~min}$.

Table 1. Primers and probe used in a multiplex TaqMan assay for detection and quantification of Plasmodiophora brassicae

\begin{tabular}{|c|c|c|c|}
\hline Primer, probe name ${ }^{a}$ & Sequence $\left(5^{\prime} \text { to } 3^{\prime}\right)^{b}$ & Target region ${ }^{c}$ & $\begin{array}{l}\text { Amplified } \\
\text { length (bp) }\end{array}$ \\
\hline \multicolumn{4}{|l|}{ P. brassicae } \\
\hline $\mathrm{DC} 1 \mathrm{~F}$ & CCT AGC GCT GCA TCC CAT AT & ITS1 of $P$. brassicae & 90 \\
\hline $\mathrm{DC} 1 \mathrm{mR}$ & CGG CTA GGA TGG TTC GAA A & & \\
\hline PB1 & [6-FAM] CCA TGT GAA CCG GTG AC [NFQ-MGB] & & \\
\hline \multicolumn{4}{|l|}{ pDSK-GFPuv1 } \\
\hline PBGFPuv3F & CCT AGC GCT GCA TCC CAT ATC GAT GGC CCT GTC CTT TTA C & $\begin{array}{l}\text { GFPuv gene in } \\
\text { pDSK-GFPuv1 plasmid }\end{array}$ & 116 \\
\hline PBGFPuv3R & CGG CTA GGA TGG TTC GAA AGT GTA ATC CCA GCA GCA GTT A & & \\
\hline GFP1 & [VIC] ACC ATT ACC TGT CGA CAC AAT CTG CCC T [NFQ-MGB] & & \\
\hline
\end{tabular}

Table 2. Evaluation of the specificity of primers and probes designed from the internal transcribed spacer 1 region of the Plasmodiophora brassicae genome using quantitative polymerase chain reaction (qPCR) and PCR

\begin{tabular}{|c|c|c|c|}
\hline $\begin{array}{l}P . \text { brassicae pathotype } \\
\text { or fungal species }\end{array}$ & Isolation source & Accession number & Amplification outcome \\
\hline P. brassicae $\mathrm{P} 2$ & Shanghai pak choy, clubbed roots & $\ldots$ & Amplified \\
\hline P. brassicae $\mathrm{P} 3$ & Shanghai pak choy, clubbed roots & $\ldots$ & Amplified \\
\hline P. brassicae $\mathrm{P} 5$ & Shanghai pak choy, clubbed roots & $\ldots$ & Amplified \\
\hline P. brassicae $\mathrm{P} 6$ & Canola, clubbed roots & $\ldots$ & Amplified \\
\hline P. brassicae $\mathrm{P} 8$ & Shanghai pak choy, clubbed roots & $\ldots$ & Amplified \\
\hline Epicoccum nigrum & Sclerotia of Sclerotinia sclerotiorum ${ }^{\mathrm{a}}$ & JN689342.1 & Not amplified \\
\hline Fusarium acuminatum & Sclerotia of $S$. sclerotiorum ${ }^{\mathrm{a}}$ & HM068320.1 & Not amplified \\
\hline F. equiseti & Sclerotia of S. sclerotiorum ${ }^{\text {a }}$ & EU595566.1 & Not amplified \\
\hline F. oxysporum & Sclerotia of S. sclerotiorum ${ }^{\text {a }}$ & DQ535184.1 & Not amplified \\
\hline Penicillium citrinum & Sclerotia of S. sclerotiorum ${ }^{\mathrm{a}}$ & FJ765031.1 & Not amplified \\
\hline S. sclerotiorum & Sclerotia of S. sclerotiorum ${ }^{\mathrm{a}}$ & $\ldots$ & Not amplified \\
\hline Trichoderma hamatum & Sclerotia of S. sclerotiorum a & JQ040347.1 & Not amplified \\
\hline Alternaria brassicicola & Shanghai pak choy ${ }^{\mathrm{b}}$ & $\ldots$ & Not amplified \\
\hline F. oxysporum & Celery ${ }^{b}$ & $\ldots$ & Not amplified \\
\hline Fusarium spp. & Carrot $^{\mathrm{b}}$ & $\ldots$ & Not amplified \\
\hline Phytophthora infestans & Tomato $^{\mathrm{b}}$ & $\ldots$ & Not amplified \\
\hline Rhizoctonia solani & Spinach $^{\mathrm{b}}$ & $\ldots$ & Not amplified \\
\hline S. cepivorum & Onion ${ }^{\mathrm{b}}$ & $\ldots$ & Not amplified \\
\hline S. minor & Lettuce $^{\mathrm{b}}$ & $\ldots$ & Not amplified \\
\hline S. sclerotiorum & Carrot $^{\mathrm{b}}$ & $\ldots$ & Not amplified \\
\hline
\end{tabular}

${ }^{a}$ Sclerotia of S. sclerotiorum were collected at the Muck Crop Research Station in 2011.

b Isolated from infected plants at the Muck Crop Research Station in 2013. 
Validation of the qPCR assay. To develop a TaqMan assay, a range of $P$. brassicae resting spore concentrations $\left(0,10^{2}, 10^{3}\right.$, $10^{4}, 10^{5}, 10^{6}, 10^{7}$, and $10^{8}$ ) were added directly into the Microbead tubes provided with the Power Soil DNA isolation kit. There were three replicates for each treatment. DNA extraction and purification protocols were performed according to the manufacturer's instructions. A mechanical Bead Ruptor (Omni International, Inc., Kennesaw, GA) was used to homogenize each sample for $1 \mathrm{~min}$ at high speed. The gDNA derived from $P$. brassicae resting spore concentrations (from $10^{3}$ to $10^{8}$ spores) was used as a standard series in further qPCR assays and as treatments in validation of the multiplex assay. To determine the quantities of $P$. brassicae gDNA corresponding to the resting spore concentrations used in the standard series, the gDNA concentration derived from $10^{8} P$. brassicae resting spores was diluted in 10-fold increments down to the concentration equivalent to $10^{2}$ resting spores. The gDNA concentration in the dilution series was measured using a Qubit fluorometer (Life Technologies, Eugene, OR).

Development of the CIPC. To identify changes in amplification efficiency resulting from PCR inhibitors, an IC was developed using a plasmid (pDSK-GFPuv1) containing a variant of the gene coding for green fluorescent protein (GFPuvl) (30). The origin of green fluorescent protein (GFP) is a jellyfish; therefore, it was assumed that this DNA would not be present in soil. For amplification of GFPuvl, forward (PBGFPuv3F) and reverse (PBGFPuv3R) hybrid primers were designed based on plasmid sequence (pDSK-GFPuv1), with binding sites for the forward and reverse amplification primers for $P$. brassicae ligated to the $5^{\prime}$ ends. Incorporation of the $P$. brassicae sites would generate an amplicon that can be amplified with DCIF and $\mathrm{DC} 1 \mathrm{mR}$ primers for $P$. brassicae. The amplification conditions were $0.4 \mu \mathrm{M}$ each hybrid primer (PBGFPuv3F and PBGFPuv3R; Table 1), $0.1 \mathrm{mM}$ dNTPs, $2 \mathrm{mM} \mathrm{MgCl} 2,1 \times$ reaction buffer, $1 \mathrm{U}$ of DNA polymerase (JumpStart Taq DNA Polymerase; Sigma-Aldrich), and $5 \mu \mathrm{l}$ of template DNA of plasmid pDSK-GFPuv1. PCR cycling conditions were $94^{\circ} \mathrm{C}$ for $2 \mathrm{~min}$ and 40 cycles of $94^{\circ} \mathrm{C}$ for $30 \mathrm{~s}, 55^{\circ} \mathrm{C}$ for $30 \mathrm{~s}, 72^{\circ} \mathrm{C}$ for $1 \mathrm{~min}$, and $72^{\circ} \mathrm{C}$ for $10 \mathrm{~min}$ in a reaction volume of $25 \mu \mathrm{l}$. Electrophoresis evaluation of this amplicon on $2 \%$ agarose gel (Ultrapure Agarose, Carlsbad, CA) and staining with ethidium bromide resulted in an amplicon (CIPC) of 116 bp (77 bp of pDSK-GFPuv1 + 39 bp of $P$. brassicae forward and reverse primers). The amplicon was treated with a Wizard SV Gel and PCR Clean-up kit (Promega Corp., Madison, WI) following the manufacturer's instructions to remove residual primers and dNTPs. The concentration of the purified CIPC amplicon was determined using a Qubit fluorometer.

Validation of the multiplex qPCR assay. To discriminate the CIPC from $P$. brassicae in the multiplex qPCR assay, a probe (GFP1) with a sequence complementary to a region of GPFuvl was used. The probe (GFP1) was labeled with the $5^{\prime}$ reporter fluorophore VIC and $3^{\prime}$ quencher dye NFQ-MGB (Applied Biosystems). To determine the amount of CIPC amplicon that does not interfere in a multiplex reaction, a 10-fold dilution series of CIPC ranging from $10^{-2}$ to $10^{-9} \mu \mathrm{g} / \mu \mathrm{l}$ was tested with concentrations of $P$. brassicae gDNA derived from $10^{3}$ to $10^{8}$ resting spores. The qPCR reaction mixture was the same as stated for the singleplex assay, except that $0.8 \mu \mathrm{l}$ of $6.25 \mu \mathrm{M}$ CIPC probe (GFP1) was added to the mastermix for the multiplex assay. Preliminary evaluations showed that $2 \mu \mathrm{l}$ of the CIPC amplicon at $5 \times 10^{-8} \mu \mathrm{g} / \mu \mathrm{l}$ $(5 \mathrm{fg} / \mu \mathrm{l})$ in $20 \mu \mathrm{l}$ of reaction mix had a quantification cycle $\left(\mathrm{C}_{\mathrm{q}}\right)$ value of 20.9 to 21.4 when multiplexed with concentrations of $P$. brassicae DNA derived from $10^{3}$ to $10^{8}$ resting spores.
Inoculated and naturally infested soil samples. The efficacy of the TaqMan assay was assessed in two mineral soils and a highorganic-matter (OM) soil (approximately $80 \%$ OM) inoculated with known amounts of resting spores of $P$. brassicae. Samples of the mineral soils were obtained from the University of Guelph research farm at Elora, ON, Canada (London loam, aquic hapludalf) and from the Agriculture and Agri-Food research farm at Saskatoon, SK, Canada (Sutherland clay-loam, vertic haploborolls). The high-OM soil (Hemic histosol) was obtained from the Muck Crop Research Station. The physical characteristics and the $\mathrm{pH}$ of the soils were measured by an accredited laboratory (Agrifood Laboratories, Guelph, ON, Canada; Table 3). Clubroot had not previously been reported at any of the sampling locations. Each soil sample was ground to a fine powder using a mortar and pestle, passed through a $355-\mu \mathrm{m}$ sieve, and dried at $37^{\circ} \mathrm{C}$ overnight. For the mineral soils, $0.25 \mathrm{~g}$ of powdered soil was added directly into the microbead tubes provided with the Power Soil DNA isolation kit. However, there was no DNA amplification from the high-OM soil when $0.25 \mathrm{~g}$ was assessed; therefore, a range of sample weights $(0.25,0.20,0.15,0.10$, and $0.05 \mathrm{~g})$ were tested and $0.10 \mathrm{~g}$ was selected for muck soil in this analysis. The soil samples-mineral $(0.25 \mathrm{~g})$ and muck $(0.10 \mathrm{~g})$-were inoculated by replacing $0.1 \mathrm{ml}$ of the solution in the microbead tubes with known concentrations of resting spores to produce concentrations of $0,10^{2}, 10^{3}, 10^{4}, 10^{5}, 10^{6}, 10^{7}$, and $10^{8}$ spores. The soil samples added to the microbead tubes were subsamples of one sample for each soil type, to minimize potential heterogeneity of DNA inhibition among the soil samples. DNA extraction and purification processes were conducted as described above. Homogenization using the mechanical Bead Ruptor was optimized to $1 \mathrm{~min}$ at high speed based on a preliminary trial using the three soil types. There were three biological replicates for each treatment.

Soil samples naturally infested with $P$. brassicae were obtained from the Muck Crop Research Station; the Agriculture and AgriFood Canada research farm at Normandin, QC, Canada (Labarre silty clay, humic gleysol); and the clubroot nursery site of Alberta Agriculture and Rural Development near Edmonton, AB, Canada (black Chernozemic loam). At each location, about $200 \mathrm{ml}$ of soil was collected from soil cores extracted from the top $10 \mathrm{~cm}$ at each of three sites. From this bulked and mixed sample, a $0.50 \mathrm{-g}$ sample was drawn and divided into two 0.25 -g samples for DNA extraction. These samples were processed as described above but were not inoculated with $P$. brassicae.

qPCR was employed to determine the quantity of $P$. brassicae gDNA in each soil sample. The $P$. brassicae gDNA from $10^{3}$ to $10^{8}$ resting spores was used to generate a standard curve. To accommodate as many target samples in a qPCR run as possible, the standard series consisted of two technical replicates for each concentration.

To determine the detection threshold of $P$. brassicae resting spores, DNA extracts of the Elora and high-OM soils were inoculated with 100 or 500 resting spores per $0.25 \mathrm{~g}$, diluted 5- and 10-fold, and assessed as described previously.

Estimation of resting spores in a sample: The $P$. brassicae gDNA from $10^{3}$ to $10^{8}$ resting spores (in 10 -fold increments) was used to generate a standard curve for the qPCR assays, as has been described previously for estimation of Enterococcus bacteria (13). Instead of using gDNA concentration directly, resting spore concentration was used to develop the standard curve (StepOne Software v.2.0; Applied Biosystems) and estimates of spore concentrations were generated as the output for $\mathrm{C}_{\mathrm{q}}$ values. However, the software

Table 3. Physical characteristics (proportion of organic matter [OM], sand, silt, and clay), texture, and $\mathrm{pH}$ of the soil types used to test the efficacy of the multiplexed TaqMan assay

\begin{tabular}{lllcccr}
\hline Location $^{\mathbf{a}}$ & Soil texture & pH & OM (\%) & Sand (\%) & Silt (\%) & Clay (\%) \\
\hline Elora, ON & Silt loam & 7.3 & 2.8 & 35 & 54 & 11 \\
Saskatoon, SK & Loam & 5.3 & 4.5 & 44 & 43 \\
MCRS, ON & Sandy loam & 5.6 & 81.4 & 50 & 45 & 5
\end{tabular}

a Soil at Elora is a London loam (aquic hapludalf), at Saskatoon is a Sutherland clay-loam (vertic haploborolls), and at the Muck Crops Research Station (MCRS) is a muck soil (hemic histosol). The description of soil texture and mineral components from the MCRS refers only to the 18.6\% mineral component of the soil 
generally did not estimate spore concentrations for samples with a $\mathrm{C}_{\mathrm{q}}$ value $>35$. It is noteworthy that the lowest value on the standard curve was $10^{3}$ spores $\left(\mathrm{C}_{\mathrm{q}} 33.5\right)$ but the linear pattern of the curve continued to $\mathrm{C}_{\mathrm{q}} 35$. Therefore, a $\mathrm{C}_{\mathrm{q}}$ value of 35 was selected as a cut-off point for accurately quantifiable data. For the samples with $\mathrm{C}_{\mathrm{q}}$ value $>35$, the approximate estimate was calculated using following formula: $1,000 / 2^{\text {(Cq sample - Cq 1,000 spores) }}$. The formula was generated based on the principle that a $100 \%$ efficient reaction in $\mathrm{PPCR}$ will yield a 10 -fold increase in PCR amplicon every 3.32 cycles $\left(\log _{2} 10=3.32\right)$ during the exponential phase of amplification (Applied Biosystems). For example, if the $\mathrm{Cq}$ of the sample was 35.5 and $\mathrm{Cq}$ for 1,000 spores was 33.5 , the estimate would be $1,000 / 2^{(35.5-33.5)}=250$ spores; concentration is reduced by half with each 1-unit increased in Cq. Because these estimates were approximate quantifications, they were referred as "detected, approximately quantified" (DAQ).

Detection of inhibition and normalization of data. The presence of inhibitors in a sample was indicated when the $\mathrm{C}_{\mathrm{q}}$ value of the CIPC rose above 21.4. If the $\mathrm{C}_{\mathrm{q}}$ value was $>24.5$ or there was no DNA amplification, the level of inhibition in the sample was considered to be too high to provide an accurate estimate of resting spore concentration, and the sample was diluted and reassessed. However, if the $\mathrm{C}_{\mathrm{q}}$ value of the CIPC was between 21.5 and 24.5, inhibition was considered to be low to moderate, and the estimate of resting spore concentration was corrected for inhibition using the formula of Bilodeau (2): correct concentration $(n)=$ the estimate concentration based on the standard curve $x(\mathrm{E}+1)^{\Delta \mathrm{Cq}}$, where $\mathrm{E}=$ efficiency and $\Delta \mathrm{C}_{\mathrm{q}}=$ $\mathrm{C}_{\mathrm{q}}$ CIPC sample $-\mathrm{C}_{\mathrm{q}}$ CIPC control (water). In the initial assessments using undiluted extracts from soil, there was no amplification of DNA. Therefore, a $10 \times$ dilution with molecular-grade water was made for each gDNA sample. Because DNA was extracted from 0.25 and $0.10 \mathrm{~g}$ of the mineral and high-OM field soil samples, the initial estimates were multiplied by 4 and 10 for mineral and highOM soil, respectively, to obtain estimates of resting spores concentration per gram.

Comparison of the SYBR Green and multiplex TaqMan assays. Inoculated mineral soil from the Elora site was used to compare the efficiency of the standard SYBR Green assay (21) with the multiplex TaqMan assay for detection and quantification of $P$. brassicae. The qPCR reaction conditions for the multiplex assay were as described above, while the SYBR Green assay was run in a $10-\mu l$ volume containing $2 \mu \mathrm{l}$ of template DNA solution, $2.5 \mu \mathrm{l}$ of $3.2 \mathrm{mM}$ primer mix, and $5.5 \mu l$ of SYBR Green PCR Master mix (Applied Biosystems) as the detection dye. Reaction conditions consisted of an initial heat denaturation step at $95^{\circ} \mathrm{C}$ for 2 min followed by 35 cycles of $95^{\circ} \mathrm{C}$ for $15 \mathrm{~s}$ and $60^{\circ} \mathrm{C}$ for $60 \mathrm{~s}$. The presence of a single amplification product at the end of each reaction was confirmed by a meltingpoint analysis.

Statistical analysis. Analysis of variance (ANOVA) and regression analyses were used to describe the relationship and best fit lines (standard curves) for $P$. brassicae gDNA obtained from $10^{3}$ to $10^{8}$ resting spores with or without the IC. The slopes and intercepts of the regression responses of standard curves were compared using Tukey's $w$ procedure, and $t$ tests and single-degree-of-freedom contrasts were used to compare treatment means of initial and corrected concentration estimates obtained in the multiplex assay and among SYBR Green and TaqMan assays. Differences were significant at $P \leq 0.05$ unless otherwise specified. All of the analyses were conducted using SAS software (version 9.3; SAS Inc.).

\section{Results}

Primer and probe specificity. The qPCR assay using primers DC1F and DC1mR and probe PB1 amplified gDNA of all of the pathotypes of $P$. brassicae and there was no amplification of gDNA from the fungi tested (Table 1). The results were confirmed by conventional PCR, where distinct $98-\mathrm{kb}$ amplicons were observed for $P$. brassicae pathotypes, whereas no bands were observed with gDNA from the fungal species (data not shown).

Validation of the singleplex qPCR assay. Single-degree-offreedom contrasts within ANOVA indicated that the standard curve for the gDNA concentrations extracted from suspensions of resting spores of $P$. brassicae $\left(10^{3}\right.$ to $10^{8}$ spores $)$ in a singleplex TaqMan assay was linear (Fig. 1). The standard curve was validated in subsequent assays. Amplification efficiency ranged from 0.92 to 1.06 and there was a strong negative correlation (range 0.99 to 1.0) between $\mathrm{C}_{\mathrm{q}}$ value and the $\log _{10}$ of $P$. brassicae resting spore concentration. Fluorometric analysis showed that the gDNA concentrations of the dilution series representing $10^{8}, 10^{7}, 10^{6}, 10^{5}, 10^{4}$, and $10^{3}$ resting spores was equivalent to $3 \times 10^{6}, 3 \times 10^{5}, 3 \times 10^{4}, 3,000,300$, and $30 \mathrm{fg} / \mu \mathrm{l}$, respectively $(n=2)$.

Similarly, a linear standard curve was obtained in the singleplex assay on a dilution series of CIPC amplicon concentrations using primers DC1F and DC1mR and CIPC-specific probe (GFP1). However, $P$. brassicae gDNA was not amplified using this combination of primers and probes (data not shown).

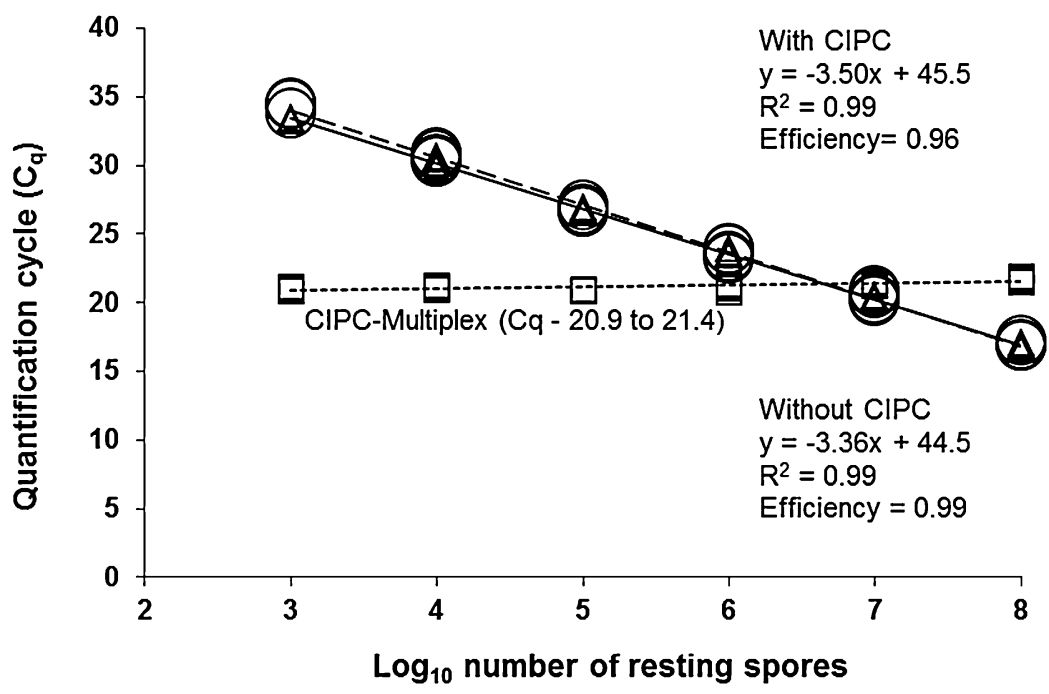

Fig. 1. Standard curves of a Plasmodiophora brassicae genomic DNA (gDNA) dilution series with quantification cycle $\left(\mathrm{C}_{\mathrm{q}}\right)$ value plotted against the log ${ }_{10}$ number of resting spores used to extract $P$. brassicae gDNA. Values represent means of two experimental units with technical duplication of each unit $(n=2)$. Triangles and regression analysis represent amplification without the competitive internal positive control $(\mathrm{CIPC})$ (standard error $[\mathrm{SE}]=0.20$ ), circles and regression analysis reflect amplification with $\mathrm{CIPC}(\mathrm{SE}=0.28)$, and the squares represent $\mathrm{CIPC}$ values (ranging from 20.9 to $21.4, \mathrm{SE}=0.16$ ) when multiplexed with gDNA obtained from various concentrations of $P$. brassicae spores. The standard deviation of the $\mathrm{C}_{\mathrm{g}}$ values of the $P$. brassicae gDNA concentrations for the technical duplicates corresponding to $10^{8}, 10^{7}, 10^{6}$, and $10^{5}$ resting spores ranged from 0.01 to 0.3 , and from $10^{4}$ and $10^{3}$ resting spores ranged from 0.1 to 0.45 , with and without CIPC. 
Validation of the multiplex qPCR assay. The reaction conditions for coamplification of $P$. brassicae and the CIPC were determined after optimizing the reaction as a singleplex assay. Using these levels as a base, a range of concentrations of primers, probes, and nucleotides was assessed with a range of CIPC concentrations. Based on these assessments, CIPC DNA at $5 \mathrm{fg} / \mu 1$ per reaction provided consistent amplification $\left(\mathrm{C}_{\mathrm{q}}\right.$ value between 20.9 to 21.4$)$ over a range of $P$. brassicae DNA concentrations from $10^{3}$ to $10^{8}$ spores, without reducing assay sensitivity or reproducibility. Inclusion of CIPC DNA did not affect the amplification efficiency, slope, or intercept of the P. brassicae standard curve $(n=2)$ (Fig. 1).

Inoculated and naturally infested soils. In the initial assessments of DNA extracted from inoculated soil samples without dilution, there was no DNA amplification. Even when diluted 10-fold, the $\mathrm{C}_{\mathrm{q}}$ values for amplification of CIPC DNA in Elora and Saskatoon soil extracts were substantially higher than the control (Table 4). After normalization, based on $\Delta \mathrm{C}_{\mathrm{q}}$, the corrected concentration estimates were significantly higher than the initial concentration estimates in diluted samples, except for one mineral soil sample inoculated with a low concentration $\left(10^{3}\right.$ spores/g of soil $)$ of resting spores. Because $\Delta \mathrm{C}_{\mathrm{q}}$ was never greater than 3.3 in the diluted samples, no further dilution was needed for the samples.

The $\mathrm{C}_{\mathrm{q}}$ values of the $\mathrm{gDNA}$ obtained from soil samples inoculated with $10^{8}, 10^{7}, 10^{6}, 10^{5}$, and $10^{4}$ spores per $0.25 \mathrm{~g}$ and diluted 10 -fold were $<35$. Similarly, samples of gDNA taken from soil inoculated with $10^{3}$ spores per $0.25 \mathrm{~g}$ and diluted 10 -fold also generally amplified successfully. The estimated concentration from the latter samples was about 20 spores (or 200 spores, after taking into account the dilution factor; Table 4). However, the $\mathrm{C}_{\mathrm{q}}$ values of these samples were $>35$; therefore, the estimates were categorized as DAQ. There was no amplification of $P$. brassicae gDNA from diluted (5- or 10-fold) samples of mineral soil or high-OM soil inoculated with 100 spores per $0.25 \mathrm{~g}$. Amplification of $P$. brassicae gDNA containing 500 spores per $0.25 \mathrm{~g}$ was observed inconsistently: five of six (in 5-fold dilutions) and two of six (in 10-fold dilutions) in mineral soil, and three of six (in 5-fold dilutions) and one of six (in 10-fold dilutions) in high-OM soil samples.

In the high-OM soil, gDNA was not amplified from 0.25-g samples (Table 5). At 10-fold dilution, the CIPC DNA was amplified with a high $\mathrm{C}_{\mathrm{q}}$ value but $P$. brassicae $\mathrm{gDNA}$ was not amplified. When a range of sample sizes was assessed, $P$. brassicae gDNA was amplified from sample weights below $0.15 \mathrm{~g}$ in 10 -fold diluted samples (Table 5). As a result, $0.10 \mathrm{~g}$ was selected as the sample weight for subsequent experiments with high-OM soil (Table 6). After normalization based on $\Delta \mathrm{C}_{\mathrm{q}}$, the corrected concentration estimates were significantly higher than the initial estimates (Table 6).

The multiplex assay amplified $P$. brassicae gDNA from all three naturally infested field soils. As observed previously with inoculated soils, after normalization based on $\Delta \mathrm{C}_{\mathrm{q}}$, the corrected concentration estimates were significantly higher than the initial estimates (Table 7). No DNA amplification was observed in sample 23-1, which was collected from a field in Quebec where no clubroot was observed in a susceptible canola cultivar the previous year (Table 8) and, therefore, was believed to be free of resting spores of $P$. brassicae.

Comparison of SYBR Green and multiplex TaqMan assays. Based on single-degree-of-freedom contrasts, there were no differences in the unadjusted estimates of resting spore concentrations for most of the treatments between the SYBR Green and multiplex TaqMan assays (Table 8). After adjustment for inhibition, however, the corrected estimates from the multiplex assay were substantially higher than initial (unadjusted) estimates from the SYBR Green and TaqMan assays (Table 8). There was no difference in the detection threshold of the two assays.

\section{Discussion}

The multiplex qPCR TaqMan assay developed in this study provided sensitive quantification of resting spores populations of $P$. brassicae from a range of soil types. This is the first assay for $P$. brassicae that includes a multiplex CIPC. An amplicon of a plasmid containing a variant of the GFP gene (GPFuv1) was developed as the CIPC. The concentration of the CIPC in each sample is low to minimize competition for the primer and nucleotide pools. Inclusion of the CIPC in the multiplex reaction provided quantification of $P$. brassicae gDNA over a wide range $\left(10^{3}\right.$ to $\left.10^{8}\right)$ of resting spore concentrations and quantification of the level of inhibition in each sample based on the difference in the CIPC $\mathrm{C}_{\mathrm{q}}$ values relative to a CIPC-only control. Quantification of the inhibition in each sample was used to improve estimates of resting spore populations, and

Table 5. Estimates of Plasmodiophora brassicae resting spore concentration from high organic matter (approximately 80\%) soil from the Muck Crops Research Station, ON inoculated with $1.0 \times 10^{8}$ resting spores and assessed in a TaqMan quantitative polymerase chain reaction assay using primers $\mathrm{DC} 1 \mathrm{~F}$ and $\mathrm{DC} 1 \mathrm{mR}$

\begin{tabular}{lccc}
\hline & \multicolumn{3}{c}{ Estimates of resting spore concentration } \\
\cline { 2 - 4 } Weight of soil $\mathbf{( g )}$ & $\mathbf{\Delta C}_{\mathbf{q}}$ & Initial $^{\mathbf{b}}$ & Corrected $^{\text {(g) }}$ \\
\hline 0.25 & 0.8 & $\mathrm{NA}$ & $\ldots$ \\
0.20 & 1.2 & $\mathrm{NA}$ & $\ldots$ \\
0.15 & 1.3 & $0.29 \times 10^{8}$ & $0.94 \times 10^{8 *}$ \\
0.10 & 1.1 & $0.36 \times 10^{8}$ & $0.97 \times 10^{8 *}$ \\
0.05 & 1.5 & $0.27 \times 10^{8}$ & $0.91 \times 10^{8 *}$ \\
\hline
\end{tabular}

a There was no amplification of DNA from the initial samples, so they were diluted 1:10. $\Delta \mathrm{C}_{\mathrm{q}}=$ quantification cycle $\left(\mathrm{C}_{\mathrm{q}}\right)$ internal control (IC) sample $-\mathrm{C}_{\mathrm{q}}$ IC control (water). NA $=$ no amplification. Asterisk $(*)$ indicates that the corrected concentration estimates differed at $P<0.05$ from the initial concentration estimates based on single-degree-of-freedom contrasts.

${ }^{\mathrm{b}}$ Each value is the mean of two biological replicates $(n=2)$, each with technical replicates, after taking into account the 10 -fold dilution factor.

Table 4. Estimates of Plasmodiophora brassicae resting spore concentrations using a multiplexed TaqMan quantitative polymerase chain reaction assay (primers DC1F and DC1mR) in artificially inoculated mineral soil collected from Elora, ON and Saskatoon, SK

\begin{tabular}{|c|c|c|c|c|c|c|}
\hline \multirow[b]{3}{*}{ Number of spores added ${ }^{b}$} & \multicolumn{6}{|c|}{ Estimates of resting spore concentrationa } \\
\hline & \multicolumn{3}{|c|}{ Elora } & \multicolumn{3}{|c|}{ Saskatoon } \\
\hline & $\Delta \mathbf{C}_{q}$ & Initial $^{\mathbf{c}}$ & Corrected & $\Delta \mathrm{C}_{\mathrm{q}}$ & Initial $^{\mathrm{c}}$ & Corrected \\
\hline$\overline{1 \times 10^{8}}$ & 2.3 & $0.23 \times 10^{8}$ & $0.92 \times 10^{8 *}$ & 1.2 & $0.32 \times 10^{8}$ & $0.85 \times 10^{8 *}$ \\
\hline $1 \times 10^{7}$ & 2.9 & $0.16 \times 10^{7}$ & $0.95 \times 10^{7 *}$ & 0.6 & $0.57 \times 10^{7}$ & $1.03 \times 10^{7 *}$ \\
\hline $1 \times 10^{6}$ & 1.5 & $0.42 \times 10^{6}$ & $1.07 \times 10^{6 *}$ & 0.8 & $0.45 \times 10^{6}$ & $0.88 \times 10^{6}$ \\
\hline $1 \times 10^{5}$ & 2.1 & $0.30 \times 10^{5}$ & $0.89 \times 10^{5 *}$ & 1.2 & $0.35 \times 10^{5}$ & $0.94 \times 10^{5 *}$ \\
\hline $1 \times 10^{4}$ & 1.4 & $0.41 \times 10^{4}$ & $1.01 \times 10^{4 *}$ & 1.0 & $0.42 \times 10^{4}$ & $0.92 \times 10^{4 *}$ \\
\hline $1 \times 10^{3}$ & 2.2 & $215^{\mathrm{d}}$ & $860 *$ & 0.9 & $369^{\mathrm{d}}$ & $776^{*}$ \\
\hline $1 \times 10^{2}$ & 2.3 & ND & $\ldots$ & 1.0 & ND & $\ldots$ \\
\hline
\end{tabular}

a There was no amplification of DNA from the initial samples, so they were diluted 1:10. $\Delta \mathrm{C}_{\mathrm{q}}=$ quantification cycle $\left(\mathrm{C}_{\mathrm{q}}\right)$ internal control (IC) sample $-\mathrm{C}_{\mathrm{q}} \mathrm{IC}$ control (water). An asterisk (*) indicates that the corrected concentration estimates differed at $P<0.05$ from the initial concentration estimates based on singledegree-of-freedom contrasts. ND = not detected.

${ }^{\mathrm{b}}$ Spores were inoculated in $0.25 \mathrm{~g}$ of soil.

${ }^{\mathrm{c}}$ Each value is the mean of two biological replicates $(n=2)$, each with technical replicates, after taking into account the 10 -fold dilution factor.

d These values lay outside of the optimized level of quantification, so they were considered "detected, approximately quantified". 
could be used to rapidly identify samples that required further dilution or even reextraction to reduce inhibition.

Most studies on quantification of a pathogen using qPCR estimate DNA weight or copies of the pathogen in the target samples based on

Table 6. Estimates of Plasmodiophora brassicae resting spores from highorganic-matter (approximately 80\%) soil from Muck Crops Research Station, ON from a TaqMan quantitative polymerase chain reaction assay using primers $\mathrm{DC} 1 \mathrm{~F}$ and $\mathrm{DC} 1 \mathrm{mR}$

\begin{tabular}{lccc}
\hline & \multicolumn{3}{c}{ Estimates of spore concentration } \\
\cline { 2 - 4 } Number of spores added $^{\mathbf{b}}$ & $\boldsymbol{\Delta \mathbf { C } _ { \mathbf { q } }}$ & Initial $^{\mathbf{c}}$ & Corrected $^{\mathbf{y}}$ \\
\hline $1 \times 10^{8}$ & 2.2 & $0.18 \times 10^{8}$ & $0.87 \times 10^{8 *}$ \\
$1 \times 10^{7}$ & 1.8 & $0.29 \times 10^{7}$ & $1.07 \times 10^{7 *}$ \\
$1 \times 10^{6}$ & 1.9 & $0.22 \times 10^{6}$ & $0.88 \times 10^{6 *}$ \\
$1 \times 10^{5}$ & 2.1 & $0.20 \times 10^{5}$ & $0.92 \times 10^{5 *}$ \\
$1 \times 10^{4}$ & 1.9 & $0.25 \times 10^{4}$ & $0.96 \times 10^{4 *}$ \\
$1 \times 10^{3}$ & 2.4 & $196^{\mathrm{d}}$ & $1,042^{*}$ \\
$1 \times 10^{2}$ & 2.1 & $\mathrm{ND}$ & $\ldots$ \\
\hline
\end{tabular}

a There was no amplification of DNA from the initial samples, so they were diluted 1:10. $\Delta \mathrm{C}_{\mathrm{q}}=$ quantification cycle $\left(\mathrm{C}_{\mathrm{q}}\right)$ internal control (IC) sample $-\mathrm{C}_{\mathrm{q}}$ IC control (water). An asterisk (*) indicates that the corrected concentration estimates differed at $P<0.05$ from the initial concentration estimates based on single-degree-of-freedom contrasts. $\mathrm{ND}=$ not detected.

b Spores were inoculated in $0.25 \mathrm{~g}$ of soil.

c Each value is the mean of two biological replicates $(n=2)$, each with technical replicates, after taking into account the 10-fold dilution factor

d These values were out of optimized level of quantification, so they were considered "detected, approximately quantified". a standard curve derived from DNA concentrations expressed as weight or copies of the pathogen $(1,3,14,20)$. This approach is required for pathogens that occur in soil or plant debris in two or more distinct forms (e.g., asexual and sexual spores) and for quantification of a pathogen in planta that has variable shape or size. However, $P$. brassicae occurs in dry soil only as uniform-sized, single-celled resting spores. For $P$. brassicae, resting spore concentration is directly equivalent to copy number or weight of amplified DNA. This equivalency was utilized to estimate $P$. brassicae concentration in soil samples based on a standard curve expressed as resting spore concentrations of $P$. brassicae. A similar methodology has been used to estimate populations of Enterococcus bacteria from fresh water samples (13).

One application of the multiplex assay with CIPC in each sample will be in research, where accurate estimates of the resting spore population may be as important as knowing that the pathogen is present. However, the most important application on the Northern Great Plains, where $P$. brassicae is spreading quickly (24), will be to reduce the potential for false-negative results when identifying infested fields. False-negative results are particularly damaging because they justify continuation of normal production at sites where the pathogen is present. This increases the likelihood that the pathogen population will increase and be dispersed before it is detected.

Inclusion of a CIPC in qPCR assays has been used to reduce falsenegative results in assessments of pathogens where there is potential for inhibition (e.g., the target is often out-competed on media by fastgrowing organisms) (1). False-negative results, which are a potential issue with the standard qPCR assay for $P$. brassicae in soil, could result from inhibition of PCR amplification by humic acids, enzymatic

Table 7. Estimates of Plasmodiophora brassicae resting spore concentration from selected field soils using the multiplexed TaqMan assay with primers DC1F and DC1mR

\begin{tabular}{|c|c|c|c|c|}
\hline \multirow[b]{2}{*}{ Location (soil type) } & \multirow[b]{2}{*}{ Sample ID } & \multicolumn{3}{|c|}{ Estimates of spore concentration ${ }^{a}$} \\
\hline & & $\overline{\Delta \mathbf{C}_{q}}$ & Initial $^{\mathbf{b}}$ & Corrected \\
\hline \multirow[t]{5}{*}{ Normandin QC (Labarre silty clay) } & $23-1$ & 1.2 & ND & $\ldots$ \\
\hline & $23-4$ & 1.9 & $2.66 \times 10^{6}$ & $8.78 \times 10^{6 *}$ \\
\hline & $28-3$ & 2.6 & $1.23 \times 10^{6}$ & $6.15 \times 10^{6 *}$ \\
\hline & 29 & 2.3 & $5.51 \times 10^{4}$ & $2.64 \times 10^{5 *}$ \\
\hline & Drapeau & 0.6 & $3.13 \times 10^{3}$ & $3.64 \times 10^{3}$ \\
\hline \multirow[t]{2}{*}{ Edmonton AB (Black Chernozemic loam) } & 1 & 2.1 & $4.72 \times 10^{4}$ & $1.42 \times 10^{5 *}$ \\
\hline & 2 & 2.3 & $7.64 \times 10^{4}$ & $3.06 \times 10^{5 *}$ \\
\hline \multirow{2}{*}{$\begin{array}{l}\text { Muck Crops Research Station ON } \\
\text { (Hemic Histosol) }\end{array}$} & Range 4-1 & 2.4 & $2.3 \times 10^{4}$ & $1.17 \times 10^{5 *}$ \\
\hline & Range 4-2 & 1.7 & $8.1 \times 10^{4}$ & $2.10 \times 10^{5 *}$ \\
\hline
\end{tabular}

a There was no amplification of DNA from the initial samples, so they were diluted 1:10. $\Delta \mathrm{C}_{\mathrm{q}}=$ quantification cycle $\left(\mathrm{C}_{\mathrm{q}}\right)$ internal control (IC) sample $-\mathrm{C}_{\mathrm{q}} \mathrm{IC}$ control (water). $\mathrm{ND}=$ not detected. An asterisk $(*)$ indicates that the corrected concentration estimates differed at $P<0.05$ from the initial concentration estimates based on single-degree-of-freedom contrasts.

${ }^{\mathrm{b}}$ Each value is the mean of two biological replicates $(n=2)$, each with technical replicates, after taking into account the 10 -fold dilution factor.

Table 8. Comparison of the estimates from SYBR Green and multiplexed TaqMan assays (using the same primers, DC1F and DC1mR) of Plasmodiophora brassicae resting spore concentration using an inoculated mineral soil from Elora ON

\begin{tabular}{|c|c|c|c|c|}
\hline \multirow[b]{2}{*}{ Number of spores added } & \multirow[b]{2}{*}{ SYBR Green (no CIPC) ${ }^{c}$} & \multicolumn{3}{|c|}{ TaqMan with CIPC } \\
\hline & & $\overline{\Delta \mathrm{C}_{\mathrm{q}}}$ & Initialc $^{\mathbf{c}}$ & Corrected \\
\hline $1 \times 10^{8}$ & $0.22 \times 10^{8}$ & 1.9 & $0.24 \times 10^{8}$ & $0.89 \times 10^{8 * *}$ \\
\hline $1 \times 10^{7}$ & $0.36 \times 10^{7}$ & 1.2 & $0.32 \times 10^{7}$ & $0.96 \times 10^{7 * *}$ \\
\hline $1 \times 10^{6}$ & $0.31 \times 10^{6}$ & 1.8 & $0.23 \times 10^{6 *}$ & $0.85 \times 10^{6 * *}$ \\
\hline $1 \times 10^{5}$ & $0.16 \times 10^{5}$ & 1.3 & $0.31 \times 10^{5 *}$ & $0.93 \times 10^{5 * *}$ \\
\hline $1 \times 10^{4}$ & $0.23 \times 10^{4}$ & 2.1 & $0.19 \times 10^{4}$ & $0.88 \times 10^{4 * *}$ \\
\hline $1 \times 10^{3}$ & $324^{\mathrm{d}}$ & 1.5 & $246^{\mathrm{d}}$ & $812 *$ \\
\hline $1 \times 10^{2}$ & ND & 1.7 & ND & $\ldots$ \\
\hline
\end{tabular}

${ }^{a} \mathrm{CIPC}=$ competitive internal positive control. $\Delta \mathrm{C}_{\mathrm{q}}=$ quantification cycle $\left(\mathrm{C}_{\mathrm{q}}\right)$ internal control (IC) sample $-\mathrm{C}_{\mathrm{q}}$ IC control (water). A single asterisk $(*)$ indicates that the values obtained in the TaqMan assay differed at $P<0.05$ from the SYBR Green based on single-degree-of-freedom contrasts. A double asterisk (**) indicates that the corrected concentration estimates differed at $P<0.05$ from the initial concentration estimates in both assays based on single-degree-of-freedom contrasts. ND = not detected.

b Spores were inoculated into $0.25 \mathrm{~g}$ of soil.

c There was no amplification of DNA from the initial samples, so they were diluted 1:10. Each value is the mean of two biological replicates $(n=2)$, each with technical replicates, after taking into account the 10 -fold dilution factor.

d These values were outside of the optimized level of quantification, so they should be considered "detected, approximately quantified. 
inhibitors, phenolic compounds, heavy metals, nontarget DNA, and contaminants, and even clay particles in soil $(2,18)$. Dilution of the extracted DNA reduces the effect of inhibitors in many samples. However even after dilution, inhibition of $P$. brassicae gDNA amplification occurred in samples from all of the soil types assessed. Use of the CIPC to calibrate the inhibition provided a more accurate assessment of the level of $P$. brassicae in each sample but also identified samples where additional purification steps are required to produce a reliable assessment.

A CIPC competes with the amplification target for all the resources in a reaction mix, including primers (3); therefore, choosing the correct $\mathrm{C}_{\mathrm{q}}$ for CIPC to detect DNA amplification inhibition due to PCR inhibitors in the sample is important. A range of $\mathrm{C}_{\mathrm{q}}$ values for CIPC varying from 20 to 30 has been used by previous researchers in multiplex detection assays $(3,12,13,19,23)$. In the current assay, $C_{q}$ values for CIPC concentrations from 21 to 27 could be used to detect DNA amplification inhibition in a sample (data not shown) but changing the $\mathrm{C}_{\mathrm{q}}$ value may affect the corrected estimate of spore concentration.

One disadvantage of diluting a sample is that, at very low levels of inoculum, dilution may take the sample below the level of detection (2). In the current study, pathogen detection was inconsistent for samples containing 100 or 500 spores per $0.25 \mathrm{~g}$ of soil. Reducing dilution as a strategy to increase the frequency of detection of low concentrations of resting spores might have a negative impact on quantification, because samples with 5-fold dilution generally had a higher $\Delta \mathrm{C}_{\mathrm{q}}$ value than 10 -fold dilution. A high $\Delta \mathrm{C}_{\mathrm{q}}$ indicates that confidence in the quantification is reduced. Similarly, this approach would not be effective for samples where the target gDNA amplification is completely inhibited. Additional purification steps (e.g., magnetic beads and columns) could be included to maximize removal of PCR inhibitors (3) and increase detection sensitivity. In high-OM soils, humic acid is reported as a major cause of the DNA inhibition and specific procedures are often required to extract and amplify DNA from these samples (33). In the initial assessments of resting spore populations at the heavily infested OM site, no amplification of target gDNA was observed. However, the CIPC was amplified, which ruled out that humic acid as the cause of inhibition of DNA amplification. By assessing factors such as time and speed of the homogenization and weight of the sample, it was determined that the weight of the sample had an important impact on DNA amplification in the high-OM samples. High-OM soils are lighter and have a larger volume per gram than mineral soils; therefore, the quantity of buffer $(0.5 \mathrm{ml})$ provided in the DNA isolation kit was not adequate for this large volume of soil. We concluded that use of a smaller $(0.1 \mathrm{~g})$ amount of high-OM soil is more suitable for the amount of the buffer provided in the extraction tubes. Kits that allow larger amounts of soil to be processed are available but would substantially increase the cost of the assay.

In the comparison of the SYBR Green and multiplex TaqMan assays, the initial estimate of gDNA from inoculated mineral soil was similar. The difference in the assays was the presence or absence of a CIPC. Estimates from the multiplex assay after correction for inhibition were substantially and consistently higher (two to seven times) than from the SYBR Green assay. Without a CIPC, resting spore concentrations could be underestimated because of the presence of inhibitors, even when the samples were diluted (12). There was no difference in the detection limit of the two assays, likely as a result of using the same primer set.

In this study, an accurate and sensitive one-step multiplex TaqMan assay was developed for detection and quantification of P. brassicae gDNA in mineral soils. Also, a modification of the assay was developed for use in soils with high OM content. This one-step multiplex assay represents an improvement over previous assays in that the presence of a CIPC in the multiplex saves time and resources by permitting correction of estimates in a single run when inhibition is low to moderate. Inclusion of the CIPC in this assay provides more accurate estimates of resting spore populations in soil but should also reduce the potential for false negatives caused by DNA amplification inhibitors, which can have important consequences for subsequent clubroot management strategies.

\section{Acknowledgments}

We thank G. J. Bilodeau for input in method development; M. Raizada for providing the pDSK-GFPuv1 plasmid for development of the internal control; D. Pageau for providing field soil samples from Quebec; J. Zhang and C. Grainger for technical assistance with qPCR; and the Clubroot Risk Mitigation Initiative of Agriculture and Agri-Food Canada, the Canola Council of Canada, the Western Grains Research Fund, Sask Canola, and the Agriculture Development Fund of Saskatchewan for financial support.

\section{Literature Cited}

1. Atallah, Z. K., Bae, J., Jansky, S. H., Rouse, D. I., and Stevenson, W. R. 2007. Multiplex real-time quantitative PCR to detect and quantify Verticillium dahliae colonization in potato lines that differ in response to Verticillium wilt. Phytopathology 97:865-872.

2. Bilodeau, G. J. 2011. Quantitative polymerase chain reaction for the detection of organisms in soil. CAB Rev. Perspect. Agric. Vet. Sci. Nutr. Nat. Resour No. 014, Oxon, UK

3. Bilodeau, G. J., Koike, S. T., Uribe, P., and Martin, F. N. 2012. Development of an assay for rapid detection and quantification of Verticillium dahliae in soil. Phytopathology 102:331-343.

4. Cao, T., Tewari, J., and Strelkov, S. E. 2007. Molecular detection of Plasmodiophora brassicae, causal agent of clubroot of crucifers, in plant and soil. Plant Dis. 91:80-87.

5. Cullen, D. W., Toth, I. K., Pitkin, Y., Boonham, N., Walsh, K., Barker, I., and Lees, A. K. 2005. Use of quantitative molecular diagnostic assays to investigate Fusarium dry rot in potato stocks and soil. Phytopathology 95: 1462-1471.

6. Deora, A., Gossen, B. D., and McDonald, M. R. 2013. Cytology of infection, development and expression of resistance to Plasmodiophora brassicae in canola. Ann. Appl. Biol. 163:56-71.

7. Dixon, G. R. 2009. The occurrence and economic impact of Plasmodiophora brassicae and clubroot disease. J. Plant Growth Regul. 28:194-202.

8. Dixon, G. R. 2009. Plasmodiophora brassicae in its environment. J. Plant Growth Regul. 28:212-228.

9. Faggian, R., Bulman, S. R., Lawrie, A. C., and Porter, I. J. 1999. Specific polymerase chain reaction primers for the detection of Plasmodiophora brassicae in soil and water. Phytopathology 89:392-397.

10. Faggian, R., and Strelkov, S. E. 2009. Detection and measurement of Plasmodiophora brassicae. J. Plant Growth Regul. 28:282-288.

11. Gossen, B. D., Deora, A., Peng, G., Hwang, S. F., and McDonald, M. R. 2014. Effect of environmental parameters on clubroot development and the risk of disease spread. Can. J. Plant Pathol. 36(S1):37-48.

12. Gregory, J. B., Litaker, R. W., and Noble, R. T. 2006. Rapid one-step quantitative reverse transcriptase PCR assay with competitive internal positive control for detection of enteroviruses in environmental samples. Appl. Environ. Microbiol. 72:3960-3967.

13. Haugland, R. A., Siefring, S. C., Wymer, L. J., Brenner, K. P., and Dufour, A. P. 2005. Comparison of Enterococcus measurements in freshwater at two recreational beaches by quantitative polymerase chain reaction and membrane filter culture analysis. Water Res. 39:559-568.

14. Hogg, A. C., Johnston, R. H., Johnston, J. A., Klouser, L., Kephart, K. D., and Dyer, A. T. 2010. Monitoring Fusarium crown rot populations in spring wheat residues using quantitative real-time polymerase chain reaction. Phytopathology 100:49-57.

15. Hoorfar, J., Malorny, B., Abdulmawjood, A., Cook, N., Fach, P., and Wagner, M. 2004. Practical considerations in design of internal amplification controls for diagnostic PCR assays. J. Clin. Microbiol. 42:1863-1868.

16. Howard, R. J., Strelkov, S. E., and Harding, M. W. 2010. Clubroot of cruciferous crops-New perspectives on an old disease. Can. J. Plant Pathol. 32:43-57.

17. Ito, S., Maehara, T., Tanaka, S., Kameya-Iwaki, M., Yano, S., and Kishi, F. 1997. Cloning of a single-copy DNA sequence unique to Plasmodiophora brassicae. Physiol. Mol. Plant Pathol. 50:289-300.

18. Lievens, B., and Thomma, B. P. H. J. 2005. Recent developments in pathogen detection arrays: Implications for fungal plant pathogens and use in practice. Phytopathology 95:1374-1380.

19. Lole, K. S., and Arankalle, V. A. 2006. Quantitation of hepatitis B virus DNA by real-time PCR using internal amplification control and dual TaqMan MGB probes. J. Virol. Methods 135:83-90.

20. Malvick, D. K., and Impullitti, A. E. 2007. Detection and quantification of Phialophora gregata in soybean and soil samples with a quantitative, realtime PCR assay. Plant Dis. 91:736-742.

21. Rennie, D. C., Manolii, V. P., Cao, T., Hwang, S. F., Howard, R. J., and Strelkov, S. E. 2011. Direct evidence of surface infestation of seeds and tubers by Plasmodiophora brassicae and quantification of spore loads. Plant Pathol. 60:811-819.

22. Rosenstraus, M., Wang, Z., Chang, S. Y., DeBonville, D., and Spadoro, J. P. 1998. An internal control for routine diagnostic PCR: Design, properties, and effect on clinical performance. J. Clin. Microbiol. 36:191-197.

23. Stelzl, E., Muller, Z., Marth, E., and Kessler, H. H. 2004. Rapid quantification of Hepatitis B virus DNA by automated sample preparation and real-time PCR. J. Clin. Microbiol. 42:2445-2449.

24. Strelkov, S. E., and Hwang, S. F. 2014. Clubroot in the Canadian canola crop: 10 years into the outbreak. Can. J. Plant Pathol. 36(S1):27-36. 
25. van Gent-Pelzer, M. P. E., Krijger, M., and Bonants, P. J. M. 2010. Improved real-time PCR assay for detection of the quarantine potato pathogen, Synchytrium endobioticum, in zonal centrifuge extracts from soil and in plants. Eur. J. Plant Pathol. 126:129-133.

26. Von Felten, A., Défago, G., and Maurhofer, M. 2010. Quantification of Pseudomonas fluorescens strains F113, CHA0 and Pf153 in the rhizosphere of maize by strain-specific real-time PCR unaffected by the variability of DNA extraction efficiency. J. Microbiol. Methods 81:108-115.

27. Wallenhammar, A. C. 1999. Monitoring and control of Plasmodiophora brassicae in spring oilseed brassica crops. Doctoral Thesis. Acta Univ. Agric. Sueciae, Agrar. 183. Swedish Univ. Agric. Sci. Uppsala, p. 53

28. Wallenhammar, A. C., Almquist, C., Söderström, M., and Jonsson, A. 2012. In-field distribution of Plasmodiophora brassicae measured using quantitative real-time PCR. Plant Pathol. 61:16-28.
29. Wallenhammar, A. C., and Arwidsson, O. 2001. Detection of Plasmodiophora brassicae by PCR in naturally infested soils. Eur. J. Plant Pathol. 107:313-321.

30. Wang, K., Kang, L., Anand, A., Lazarovits, G., and Mysore, K. S. 2007 Monitoring in planta bacterial infection at both cellular and whole-plan levels using the green fluorescent protein variant GFPuv. New Phytol 174:212-223.

31. Ward, B. E., Foster, S. J., Fraaije, B. A., and Cartney, H. A. M. C. 2004. Plant pathogen diagnostics: Immunological and nucleic acid-based approaches. Ann. Appl. Biol. 145:1-16.

32. Williams, P. H. 1966. A system for the determination of race of Plasmodiophora brassicae that infect cabbage and rutabaga. Phytopathology 56:624-626.

33. Zhou, J., Bruns, M. A., and Tiedje, J. M. 1996. DNA recovery from soils of diverse composition. Appl. Environ. Microbiol. 62:316-322. 